\title{
Research and Application of Power Engineering Science and Technology Project Management Based on All Life-cycle
}

\author{
Yingcui Chen ${ }^{1}$, Wangyuan $\mathrm{Xie}^{1}$, and Xinru $\mathrm{Yu}^{1 *}, \mathrm{Chao} \mathrm{Wu}^{1}$ \\ ${ }^{1}$ China Electric Power Research Institute, 100192 Xiaoying East Road, Beijing, China
}

\begin{abstract}
The electric power industry is an important chain in the energy revolution and one of the most important basic industries. At the same time, it is also facing the technology collision and industry innovation brought by various emerging technologies, which constantly promotes the development of the electric power industry in the direction of safety, intelligence and cleanness. Power grid enterprises have a great demand for scientific research and innovation, and the average annual investment in scientific research has exceeded 100 million yuan. With the increasing investment in scientific research and development of power enterprises year by year, the demand for systematic, scientific and efficient management system for scientific and technological projects is becoming increasingly urgent. In view of the shortcomings of the traditional project management mode, this study establishes the corresponding management and evaluation mechanism by combining with the whole life cycle management method of modern project management, realizes the transformation of power enterprise science and technology project management to high efficiency, high quality, specialization and scientization, and promotes the innovation and integration development of traditional technology and emerging technology. The all life-cycle management mode has been widely applied in major power grid projects. By integrating superior resources, breaking through major engineering technology research and development, giving full play to the innovation of projects and avoiding research and development risks, it explores the development direction of science and technology project management in energy industry and improves the industry management level.
\end{abstract}

\section{Introduction}

With the introduction and application of modern project management theory and thought in China, great changes have taken place in the management of science and technology projects, and a scientific and reasonable management system, management mode and management mechanism, as well as an increasingly perfect management policy and management system have been initially formed. [1]However, there are many deficiencies in China's science and technology project management, such as project management is relatively scattered and lack of organization standardization; the scale of the project is small, the subject is isolated, and there is no systematic and overall consideration; the effective process supervision and supervision mechanism has not been established in the project implementation stage; the process of project $\mathrm{R} \& \mathrm{D}$, achievement promotion and industrial transformation is out of touch, and different management methods are not established according to the characteristics of different types of science and technology projects; lack of science and technology project evaluation mechanism, it is difficult to form a complete closed-loop control.

The whole life cycle theory is one of the important achievements of modern project management theory. From the perspective of the whole life cycle, we study the science and technology projects. In the science and technology project management of China's power industry, we emphasize the whole process management and overall control of the project, which is conducive to improving the performance of science and technology project management and achieving the goal of successful management of science and technology projects. Through the adoption of life cycle management and control means, the establishment of corresponding management and evaluation mechanism, and the integration of advantageous resources, we have made a breakthrough in major engineering technology research and development, and at the same time led the management level of science and technology projects in the energy industry. [2]

\section{Life-cycle feasibility analysis of power science and technology projects}

\subsection{Characteristics of power technology project management}

Science and technology project management, usually refers to the dynamic activity project management process of science and technology project, which is effective to utilize human, financial, material and other scientific and technological resources through coordinating various

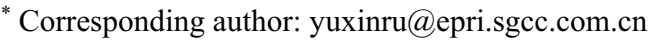


relations related to science and technology projects, and promoting the realization of scientific and technological project objectives is very complex, and it needs the joint participation of science and technology management experts and personnel with multi-disciplinary knowledge. The management of science and technology projects in the power industry has the following characteristics, innovative, uncertainty and clear directivity. [3-5]

Innovation is the most fundamental attribute of science and technology project which is different from other types of projects. Innovation of power science and technology project management not only refers to the innovation of scientific research results, but also the innovation of management methods. The innovation of management method is to flexibly formulate practical management mode and method, develop unique management ideas, specific project management, and realize effective management of single project in combination with the characteristics of the project, including the fields, disciplines and achievements.

Another remarkable feature of power science and technology project management is that the scientific and technological project has uncertainty, which is objective, and the specific performance is as follows:

1) Uncertainty of the goal. The creation characteristics of science and technology projects determine the important position of timeliness in research and development. In the actual implementation process, the realization of association technique objectives of its own scientific and technological projects may be limited due to the constraints of related technologies, or the breakthrough of other related technologies may make the association technique objectives of its own scientific and technological projects meaningless, or the project will be changed due to new problems, etc., which will cause slow progress of the project, even failed or terminated. Therefore, the management of science and technology projects is very difficult in the control of planning, funds and quality control. The unknown factors in the implementation have more influence, and the gap between research results and expected objectives is likely to be relatively large.

2) Uncertainty of technology. The factors of technology itself are also uncertain. A technology with low maturity will increase the workload and difficulty of scientific research on the one hand, and the possibility of failure on the other hand. At the same time, because some advanced technologies may not be operable, it is not necessary to have the expected effect on the research projects.

3) Uncertainty of the evaluation criteria. For other projects, the formulation of evaluation standards is relatively simple, the most fundamental is to calculate the deviation between the expected time and budget cost of the project and the specified indicators. The evaluation indicators can be quantitatively evaluated according to the operation data. On the contrary, for science and technology projects, the evaluation indexes are mostly non quantifiable or qualitative indicators, and the evaluation index system is difficult to standardize and unify. Therefore, it is necessary to establish different evaluation standards or add scientific and reasonable elastic indicators to different types of projects for project evaluation.

Other remarkable characteristics of science and technology projects is that their contents are specific and have clear pertinence. Therefore, the management of science and technology projects has a clear direction. The clear direction of science and technology project management means that through the management of the whole process of science and technology projects, the purpose of solving the common and key technological breakthroughs restricting the development of the industry is achieved, and the expected economic, social and environmental benefits can be achieved through the breakthrough of technology.

\subsection{Characteristics of life-cycle management}

The whole-life-cycle refers to a series of stages from the beginning to the end of a project. Project phases are usually arranged in chronological order. The name and number of phases depend on the management and control needs of one or more participating organizations, the characteristics of the project itself and its application field. The division of stages can be based on the availability of funds, functional objectives, delivery time of achievements, specific time nodes or specific milestones, etc. A stage usually has a time limit, with a start point, an end point, or a control point. The end of one phase is usually the beginning of the next. The project life cycle can be determined or adjusted according to the characteristics of the organization or industry, or the characteristics of the technology used.

Based on the whole process of the project, the all lifecycle management of the project emphasizes the systematicness and overall situation of the project, and applies the all life-cycle theory to the management of science and technology projects

1) A unified project management method is provided. The characteristics of science and technology projects determine that the achievements or objectives of each science and technology project are very different, and the management methods of specific projects are also different. Project life-cycle management describes the commonness of project management, provides a simple and universal analysis method, which is convenient to communicate with high-level decision makers or people who do not understand the details of the project, and is conducive to grasp the science and technology projects from the overall perspective.

2) It is conducive to the optimal overall benefit of the project. The concept of project life-cycle management is based on the integrity of the project, which has strong systematicness. Through the improvement of the management level and the optimization of the management process in each stage of the life-cycle, the goal of improving the overall comprehensive benefits of the project can be achieved.

3) It is conducive to the optimal allocation of resources. In the project life cycle, with the change of the project stage time, the input cost presents regular changes. According to the characteristics of the whole life cycle, it 
is conducive to maximize the resource efficiency to control the personnel, funds, facilities, etc.

4) It is conducive to the transformation of project achievements. The research results of research institutions are not targeted and stay in theory or laboratory, while enterprises or industrial units have a strong demand for scientific and technological innovation, and the industry chain is not smooth, which makes the transformation of scientific and technological achievements more difficult. The application of life cycle theory in project management is conducive to grasp the direction of project research according to the complete innovation chain, and effectively solve the problem of disconnection between research and development and achievement transformation.

5) It is helpful to improve the scientific literacy of personnel and the management level of management personnel. The end of each stage in life cycle management is also the beginning of the next stage. The completion of the previous stage directly affects the effect of the next stage, which requires researchers and managers to have a good sense of the overall situation and a strong sense of responsibility.

It can be seen that the all life-cycle concept has guiding significance for the management of science and technology projects. The application of the all life-cycle concept in the management of science and technology projects can effectively avoid the uncertainty in the management of science and technology projects, realize the project orientation, and give full play to the innovation of scientific researchers and science and technology projects by using scientific management methods.

\section{Life-cycle management model and evaluation system}

\subsection{Life cycle model of science and technology project based on process}

Science and technology projects can be divided into several stages according to the whole management process, and each stage can be subdivided into many sub stages, as shown in Figure 1.

Taking the new product development project as an example, its life cycle includes: (1)investigation stage; (2) conception stage; (3) scheme selection stage; (4) development decision stage; (5) design stage; (6) trial production stage; (7)test stage; (8)evaluation appraisal; (9) volume production stage; (10) marketing stage. Each stage has verifiable results.

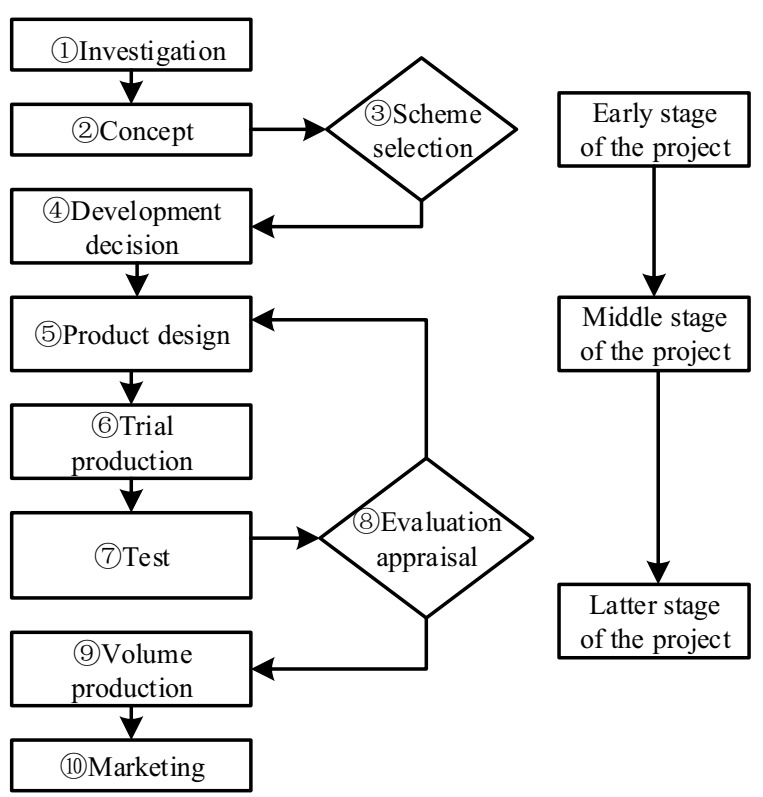

Figure 1 Life cycle model of science and technology project (1) - 4can be divided into the early stage of the project;

(5) - (7) can be called the medium-term stage of the project;

(8) - (10) the stage can be called the later stage of the project.

\subsection{Research project evaluation system based on all life-cycle}

Analytic hierarchy process (AHP) is used to evaluate scientific research projects. The evaluation index successive level is established, and three-level index system is constructed: target level, analysis level and index level. The mid-term target layer is; process management evaluation, research capability evaluation, scientific and technological achievements evaluation and comprehensive benefit evaluation. The analysis level is: process management evaluation covers project approval, coordination and organization ability, final acceptance and follow-up work evaluation; research ability evaluation covers foundation and team building; scientific and technological achievements are evaluated in two aspects: scientific and technological content and technological value; the comprehensive benefits include economic benefits, social benefits and the impact of science and technology. The index layer is subdivided into 31 sub-indexes. In the multi-level structure of the evaluation index system, several indexes under the same level belong to the upper index, which is the concrete reflection of the upper index. The importance of the lower level indicators is different, which needs to be adjusted by giving the index weight. The weight values of all the lower level indicators on the same level are between $0-1$, and the sum of the weights of all the lower level indicators is 1 , as shown in Table 1.

1) Process management evaluation evaluates the management level and execution of the whole process of project approval, implementation, acceptance and filing, which provides reference for the improvement of management level of follow-up science and technology projects. The rationality index evaluates the compliance 
and rationality of the project, and the demand index evaluates the combination of the project and the actual work. Coordinate the evaluation of organizational capacity, progress management and control, and timely rate of funds in place. Conclusion acceptance evaluation acceptance data submission quality, deviation degree of technical objectives and plans, deviation degree of cost implementation are evaluated as indicators.

Table 1. Evaluation index system of science and technology project based on all life-cycle

\begin{tabular}{|c|c|c|}
\hline Target layer & Analysis layer & Index layer \\
\hline \multirow{4}{*}{$\begin{array}{c}\text { Process } \\
\text { management }\end{array}$} & $\begin{array}{c}\text { Project } \\
\text { evaluation }\end{array}$ & Demand Normative \\
\hline & $\begin{array}{c}\text { Coordination and } \\
\text { organization } \\
\text { ability }\end{array}$ & $\begin{array}{c}\text { Progress control } \\
\text { Timeliness of funds }\end{array}$ \\
\hline & $\begin{array}{l}\text { Final acceptance } \\
\text { evaluation }\end{array}$ & $\begin{array}{l}\text { Acceptance data } \\
\text { submission } \\
\text { Target deviation } \\
\text { Cost deviation } \\
\end{array}$ \\
\hline & $\begin{array}{l}\text { Follow up work } \\
\text { evaluation }\end{array}$ & $\begin{array}{l}\text { Leading organization rate } \\
\text { Archives administration }\end{array}$ \\
\hline \multirow{2}{*}{$\begin{array}{l}\text { Research } \\
\text { capability }\end{array}$} & $\begin{array}{l}\mathrm{R} \& \mathrm{D} \\
\text { Foundation }\end{array}$ & $\begin{array}{l}\text { R \& D capability } \\
\text { Hardware support }\end{array}$ \\
\hline & Team building & $\begin{array}{l}\text { Personnel training } \\
\text { Entrusted rate } \\
\text { Research integrity }\end{array}$ \\
\hline \multirow[b]{2}{*}{$\begin{array}{l}\text { Scientific } \\
\text { technological } \\
\text { achievements }\end{array}$} & $\begin{array}{l}\text { Technology } \\
\text { content }\end{array}$ & $\begin{array}{c}\text { Paper } \\
\text { Monograph } \\
\text { Reward } \\
\text { Patent } \\
\end{array}$ \\
\hline & Technical value & $\begin{array}{c}\text { Importance of research } \\
\text { field } \\
\text { Research difficulty } \\
\text { Technical level } \\
\text { Application } \\
\text { Practicability } \\
\end{array}$ \\
\hline \multirow{3}{*}{$\begin{array}{l}\text { Comprehensiv } \\
\text { e benefits }\end{array}$} & $\begin{array}{l}\text { Economic } \\
\text { performance }\end{array}$ & $\begin{array}{l}\text { cost reduction } \\
\text { Promotion income } \\
\text { Achievement } \\
\text { transformation } \\
\end{array}$ \\
\hline & $\begin{array}{l}\text { Technological } \\
\text { influence }\end{array}$ & $\begin{array}{c}\text { Improvement of labour } \\
\text { productivity } \\
\text { Energy saving impact } \\
\text { Decision making impact }\end{array}$ \\
\hline & Social results & $\begin{array}{l}\text { Company image promotion } \\
\text { Environmental effect }\end{array}$ \\
\hline
\end{tabular}

2) The basic conditions for the implementation of the research capability evaluation project are mainly evaluated for the R \& D capability, hardware support, personnel training, outsourcing degree and scientific research integrity of the project funded units, so as to provide reference for the improvement of the follow-up work.

3) The evaluation of scientific and technological achievements is an important index to measure the technical level of scientific and technological projects, and also the focus of post evaluation. It mainly evaluates the scientific and technological content and technical value of scientific and technological achievements. The content of science and technology is the embodiment of the academic level of researchers. This research takes four evaluation indicators of papers, monographs, awards and patents to evaluate from the aspects of quantity and quality. Technical value is a comprehensive evaluation of the level and influence of research achievements. This study takes five evaluation indexes: field importance, research difficulty, technical level, application scope and practicability.

4) Comprehensive benefit is to analyse the situation benefit of the transformation of scientific and technological achievements into productive forces and the economic and social benefits produced. It is one of the most important indicators of post evaluation. Its quality determines the success of a project. The evaluation scope includes economic benefit, social benefit and scientific and technological impact. Economic benefits have direct and potential benefits. Some soft topic research projects need to be continuously reflected within a few years after the completion of the project, or even reflected in other projects or projects. In this study, four evaluation indexes are selected, i.e. input-output, export earning foreign exchange, energy saving and consumption reduction, and resource utilization. The main objective of social benefit evaluation is recessive benefit, and the purpose of evaluation is to benefit the country and improve the service level. In this study, we take two evaluation indexes: promoting local economic development and environmental impact. The impact of science and technology is to evaluate the promotion of the research level in this field and the impact on the scientific research work of management units after the implementation of science and technology projects. This study takes four evaluation indicators: Science and technology promotion, decision-making impact, improving the company's image and sustainability.

5) It is of great significance to determine a reasonable index weight coefficient for evaluating the comprehensive impact of science and technology projects. There are many methods to determine the weight of indicators. The traditional method is to rely on the experience of experts. This method is limited by the experience of experts and subjective factors. When there are many and complex indicators, qualitative judgment becomes very difficult, and the weight assignment of indicators is difficult to be accurate and scientific. In order to scientifically determine the weight coefficient of each index, Delphi method and analytic hierarchy process are used in this study. Specifically, the judgment matrix is constructed by synthesizing the expert evaluation results.

The judgment matrix $Y$ can be recorded as

$$
Y=\left(Y_{n m}\right)_{n \times m}
$$

$Y n m$ represents the importance of index $Y n$ over index $Y m$, and judgment matrix represents the ratio of relative importance of each relevant element.

Each column is normalized to get the result,

$$
W_{i j}=y_{i j} / \sum_{i=1}^{n} y_{i j}
$$

Add the vectors $W i j$ by lines,

$$
W_{i}=y_{i j} / \sum_{i=1}^{n} w_{i j}
$$


Normalize $W i j$ to get the eigenvector, and calculate the approximate value of the largest eigenvalue corresponding to the eigenvector $W i$,

$$
\begin{gathered}
\emptyset_{\text {max }}=\frac{1}{n} \sum_{i=1}^{n} \frac{(A W)_{i}}{W_{i}} \\
C I=\tau_{\text {max }-n} /(n-1)
\end{gathered}
$$

The smaller the $C I$ value, the higher the degree of consistency. If $C I=0$, the judgment matrix has complete consistency. The specific importance influence in the judgment matrix needs to be determined according to the previous data and experts' comprehensive evaluation. In the process of judgment, the first thing is to ensure the gradual normalization of the conclusions. However, due to the macro and abstract nature of scientific and technological project achievements, the judgment results may be inconsistent. Therefore, the inconsistent results need to be corrected.

\section{Application of management example UHV transmission key equipment based on all life-cycle}

UHV AC transmission technology is not a simple "amplification" of HV AC transmission technology. The technical principles of engineering planning and design, equipment development, construction and operation must be established on the basis of scientific research. The development of UHV AC power transmission in China is not only facing the world-class problems of key electromagnetic and insulation technologies under high voltage and strong current, but also facing the challenges of severe natural environment such as heavy pollution and high altitude. The main problems are as follows: first, the voltage control is difficult, the UHV AC system has large transmission capacity and long distance, and the maximum voltage should be controlled below $1100 \mathrm{kV}$ under normal operation. The steady-state voltage along the line is close to the balanced distribution, but when the fault is disconnected, the voltage distribution changes suddenly and the receiving terminal voltage rises sharply, which directly threatens the safety of the system and equipment. Second, the configuration of external insulation is difficult. The external insulation of UHV AC system is large. The withstand voltage of air gap no longer increases linearly with the increase of gap distance, showing obvious saturation effect. The tower height of transmission line and the probability of lightning shielding conductor increase significantly. The serious air pollution in China leads to the significant reduction of surface flashover voltage of insulators under polluted conditions. Third, it is difficult to control the electromagnetic environment. The multi conductor system composed of UHV AC lines and substations has complex structure and large scale. The interaction between conductors is significant. The electric field intensity on the surface of charged conductors and nearby space increases, and corona discharge produces audible noise and radio interference. Fourth, it is very difficult to develop the equipment. There are more than 40 kinds of UHV AC equipment in 9 categories, including transformers and switches, as shown in Figure2. The rated parameters are high, the electric, magnetic, thermal and mechanical fields are complex, and the coordination of physical fields is complex. Linear amplification according to the existing technology will make the equipment bulky and expensive, and some equipment cannot be transported, so the development is extremely difficult. Based on the life cycle management mode, power grid enterprises adopt the following management methods:

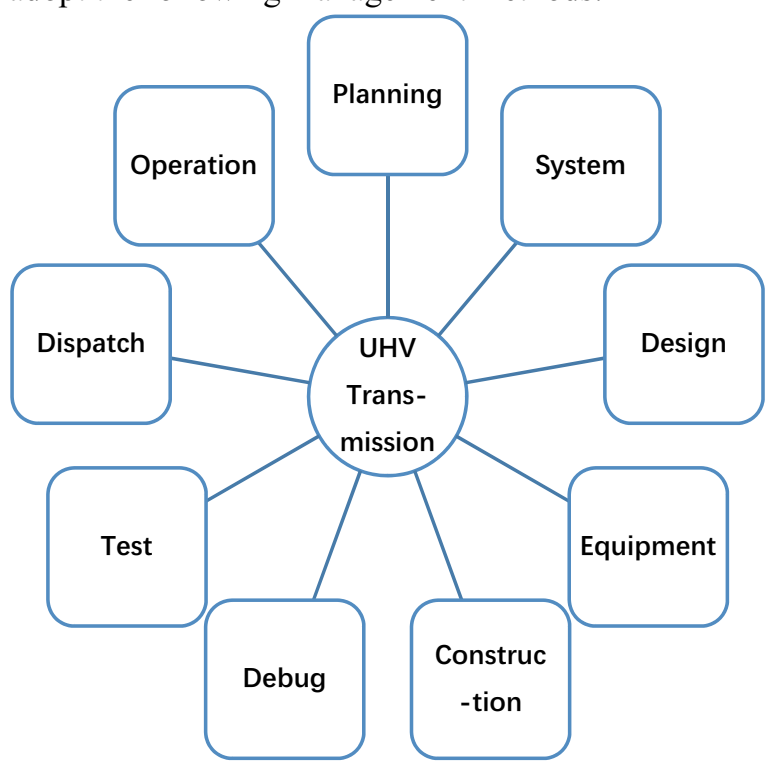

Figure. 2. Research framework of key technologies for UHVAC transmission

1) We should fully integrate scientific research resources. By adopting the open innovation mode led by the owner and jointly tackling key problems by industry, University and research, we have broken the barriers and industrial barriers between various scientific research institutions, organized scientific research institutions in the power industry, scientific research institutions in the machinery industry, and colleges and universities to jointly carry out scientific research, tap the innovation potential in the field of power technology and electrical equipment development, and give full play to the intelligence of experts in all aspects of the country, We have attached great importance to exchanges and cooperation with international counterparts, especially the former Soviet Union and other countries, concentrated resources and strength to the greatest extent, and formed a joint force of innovation, which has laid a foundation for breaking through the world-class problem of UHV AC transmission and realizing innovative development at a higher level.

2) Comprehensive coverage of engineering needs. On the basis of in-depth technical research at home and abroad, focusing on the technical characteristics of UHV AC transmission, the research framework of UHV AC transmission key technology composed of 180 subjects was studied and formulated, and various scientific research institutions were organized to carry out the whole process of planning, system, design, equipment, construction, commissioning, test and maintenance covering the early stage, construction and later stage of 
the project, the scientific research of dispatching and operation is carried out in 9 aspects. In addition to comprehensively promoting all kinds of electrical basic research under the action of large-scale, nonlinear electrical, magnetic, thermal and mechanical fields of UHVAC system, the engineering application research has been especially strengthened.

3) Efforts should be made to promote interactive verification. According to the needs of engineering design, equipment development and site construction, and in accordance with the engineering management method, the whole process of tracking and coordinating scientific research progress is carried out, and the network schedule of scientific research data exchange and achievement demand between relevant scientific research topics and relevant engineering links is formulated. Through the regular scientific research design meeting, special technical exchange and discussion, and achievement evaluation mechanism, the network schedule of scientific research data exchange and achievement demand is established. The dynamic coordination and timely optimization and adjustment of research boundary conditions and thinking methods have effectively solved the problems of interdependence, mutual restriction and mutual iteration among research results. It creates conditions for breaking through the key technical problems of UHVAC transmission in a short time.

4) Implement step-by-step and hierarchical review. In each stage of the research, relevant professional authoritative experts are organized to conduct special review, closely combined with engineering practice and test verification results to repeatedly study and demonstrate, and the leaders of State Grid Corporation of China preside over the company level review of major technical problems. Through expert discussion, intermediate review, special acceptance and company level review, the quality and level of scientific research achievements are guaranteed.

\section{Conclusion}

This study improves the management level and comprehensive benefits of science and technology projects through the implementation of differentiated management and the establishment of post evaluation index system of science and technology projects, but there is still room for further improvement in the research of science and technology project management.

1) Life cycle management mode has a high degree of matching with power industry science and technology project management mode because of its characteristics of unified management mode, maximum benefit of achievements, and optimal allocation of resources. The application of the whole life cycle in the management of science and technology projects verifies the scientificity and effectiveness of the life cycle theory, and improves the management level and efficiency of science and technology projects.

2) Aiming at the establishment stage, implementation stage and acceptance stage of science and technology projects in power industry, this paper puts forward an optimized life cycle management model and evaluation system based on process management, research capability, scientific and technological achievements and comprehensive benefits, and applies it in the R \& D project management of key equipment for UHV power transmission and transformation.

\section{References}

1. Zhou Ling. Research on key issues in power engineering project management $[\mathrm{J}]$. Real estate world, 2021 (11): 113-115

2. Yu Hongbo, yuan Wanling, Wang Min, Zhang hang, Xiong Wei, yuan Xufeng, Zou Xiaosong. Comprehensive condition assessment method of power transformer based on asymmetric closeness evidence cloud matter element model [J/OL]. Power grid technology: 1-9 [2021-06-18] https://doi.org/10.13335/j.1000-3673.pst.2020.1938.

3. Zhao Huilong. Analysis of power engineering project management $[\mathrm{J}]$. Engineering construction and design, 2020 (24): 223-224

4. Sui Yilei, Fang Xingping, Zhao Jie. Problems in power engineering construction project management and refined management strategy $[\mathrm{J}]$. Urban housing, 2020,27 (06): 230-231

5. Xu Libin, Yan Han. Analysis and Research on EPC management mode of power engineering [J]. Journal of Jiangxi Electric Power Vocational and technical college, 2020,33 (04): 6-7 